\title{
Sorption of Polycyclic Musks on Soil Components of Different Aggregate Sizes: The Effect of Organic- mineral Interactions
}

Qingwei Bu ( $\nabla$ qingwei.bu@cumtb.edu.cn )

China University of Mining and Technology - Beijing Campus

Hongmei Cao

China University of Mining and Technology - Beijing Campus

Dongkui Wu

China University of Mining and Technology - Beijing Campus

Ming Zhou

China University of Mining and Technology - Beijing Campus

\section{Research Article}

Keywords: Organic-mineral interactions, PCMs, Sorption, Koc, Different aggregate fractions

Posted Date: August 5th, 2021

DOI: https://doi.org/10.21203/rs.3.rs-767916/v1

License: (c) (i) This work is licensed under a Creative Commons Attribution 4.0 International License.

Read Full License 


\section{Abstract}

Polycyclic musks (PCMs) in soil environments have been of increasing concern because of their potential characteristic of persistence, bioaccumulation, and potential ecological risk. However, little is known about their fate process in soil environments. Here, we selected two PCMs as sorbates, namely galaxolide (HHCB) and tonalite (AHTN), to explore their sorption process in soils. Sorption batch experiments with six nature soils and their different aggregate fractions were carried out to elucidate the effect of organicmineral interactions in different aggregate sizes on sorption of these two PCMs. The possible causes of variation in the organic carbon-normalized partition coefficient $\left(K_{\mathrm{oc}}\right)$ for HHCB and AHTN have been investigated. The results indicated that the sorption contribution to different aggregate fractions to the overall sorption was dependent on both $K_{\mathrm{oc}}$ and content of each aggregate fraction. The strong influence of organic-mineral interactions on $K_{\mathrm{oc}}$ was evidenced by the large variation in $K_{\mathrm{oc}}$ on HF-treatment for both bulk soils and their different aggregate fractions. This study verified the dual effect of organicmineral interactions among selected soils. By comparing the measured and theoretical overlay $\Delta K_{\mathrm{oc}}$ values, it was indicated that the interaction between particles of different size fractions will also affect $K_{\mathrm{oc}}$ variation. This study represents a valuable contribution to the understanding of the fate processes and behaviors of PCMs in soil and its implication on the risk assessment.

\section{Introduction}

Polycyclic musks (PCMs) were used as fragrance ingredients in numerous consumer products such as cleaning agents and personal care products (Kannan et al. 2005). It was found that PCMs could have strong potentials to be bioaccumulative (Balk and Ford 1999), toxic to various aquatic organisms (Schnell et al. 2009, Gooding et al. 2006, Pedersen et al. 2009, Yamauchi et al. 2008) and accumulated in human blood, adipose tissue and even breast milk (Kannan et al. 2005, Luckenbach and Epel 2005, Reiner et al. 2007). Studies have reported the commonly detected of these PCMs in environmental compartments (Zhang et al. 2020, Sumner et al. 2010, Wang and Kelly 2017, Zhang et al. 2008, Lange, Kuch and Metzger 2015, Yang and Metcalfe 2006, Lyu et al. 2021, Azaroff et al. 2020). Given to the wide occurrence, toxic effect and ecological risk, the PCMs have raised significant concerns. Due to the hydrophobicity, PCMs are most likely to accumulate in sewage sludge or biosolids and finally discharged to the soil by sewage irrigation and sludge application (Kannan et al. 2005, Yang and Metcalfe 2006). Therefore, soils were always considered as main converge of PCMs. Based on this circumstance, studying the fate process of PCMs in soils is of great significance for understanding its environmental occurrence, risk management and control.

Sorption of organic pollutants (OPs) to soils was an environmentally important fate process that affected properties such as bioavailability, ecotoxicity, rate of degradation, and their mobility (Smernik and Kookana 2015, He et al. 2014). For hydrophobic compounds, the sorption process was considered as a partitioning between the solution and the soil organic matter (SOM), such sorption interaction was generally quantified by $K_{\text {oc }}$, the C-normalized partition coefficient (Ahmad et al. 2001). The $K_{\text {oc }}$ value was 
used to estimate the potential mobility of OPs in soils. However, the report of wide variations in $K_{\text {oc }}$ values is common in the scientific literature both between soils (Smernik and Kookana 2015, Ahangar et al. 2008, Savini et al. 2016) and between different isolated aggregate fractions (Bonfleur et al. 2016, Bonin and Simpson 2007). Many studies are devoted to elucidate the relative role of soil mineral and organic components to $K_{\mathrm{oc}}$ variation with different model contaminants. The chemical composition of SOM is known to have a substantial influence on the sorption of OPs. Smernik and Kookana (2015) reported that the $K_{\text {oc }}$ of diuron increased with the aromatic $C$ content and decreased with 0 -alkyl $C$ and alkyl $C$ content. While Ahangar et al. (2008) found that Koc was positively correlated with aryl C for diuron. Some authors hold that variations in herbicide Koc values are induced by changes in SOM aromaticity (Ahmad, Nelson and Kookana 2006, Farenhorst et al. 2010). In addition to organic matter chemistry influence the $K_{\mathrm{oc}}$ variation for specific contaminant, minerals also played important role in $K_{\mathrm{oc}}$ variation. The ratio of clay content to total organic carbon content (RCO) was used to explore the relative importance of minerals on influence OPs behavior in different soils by some investigators (Liu et al. 2008, He et al. 2014, He et al. 2011).

As a multi-component and structurally organized combination, soil matrix contained different aggregates size organic-mineral complexes (Zhou, Liu and Tang 2004). Some studies have shown that the organicmineral interaction may block adsorbable functional groups on SOM surfaces, which changed configuration of SOM when associated with minerals and resulted in a negative contribution of minerals to OPs sorption by soils (Savini et al. 2016, Smernik and Kookana 2015, Wang and Xing 2005b, Wang and Xing 2005a, Bonfleur et al. 2016). However, minerals may also positively contribute to OPs sorption in specific soils as organic-mineral interaction highly exposed (He et al. 2011). Besides, a dual function of organic-mineral interaction for OPs sorption in soils was also found (He et al. 2014, Liu et al. 2010). He et al. (2014) proposed that soil weathering might affect the contribution of minerals for OPs sorption, but there has no any direct evidence to demonstrate the effect on soil weathering.

Not only the bulk soil components, but also the component in different particle sizes had interaction each other. The chemical nature of SOM varied with different aggregate size (Amelung et al. 1998), the mechanisms of OPs sorption by organic-mineral interaction could vary as a function of particle-size distribution as well as organic matter chemistry (Liu et al. 2010). However, many researchers contribute to organic-mineral interaction in bulk soil on the $K_{\mathrm{oc}}$ variation for a specific OP, little information was obtained from organic-mineral interaction in different aggregate fractions influence on $K_{\mathrm{oc}}$ variation of PCMs in bulk soils. To further explore the sorption behavior of PCMs in bulk soils, more direct information on the effect of organic-mineral interaction in different particle size is needed.

In this study, we hypothesized that the effect of organic-mineral interaction in different particle size to sorption of bulk soils was different. Two PCMs, i.e., galaxolide (1,3,4,6,7,8-hexahydro-4,6,6,7,8,8hexamethyl-cyclopenta-(g)-2-benzopyrane, HHCB) and tonalide (7-acetyl-1,1,3,4,4,6-hexa-methyltetraline, AHTN) were selected as model PCMs because of their high production and consumption (Rimkus 1999). Our objective was to explore how organic-mineral interaction in different particle size influence $K_{\mathrm{oc}}$ 
variation of the two model PCMs among soils. To achieve it, we measured the sorption to soils and their different aggregate fractions using a batch equilibration method. The effect of organic-mineral interactions in different aggregate fractions were evaluated by comparing $K_{\mathrm{oc}}$ for before and after $\mathrm{HF}$ soils. This research is a step forward toward a better understanding of the effect of organic-mineral interactions in different aggregate fractions to PCMs sorption.

\section{Materials And Methods Reagents and soils}

HHCB (purity > 85\%), AHTN (purity > 98.5\%) and hexamethylbenzene (HMB), were purchased from Dr. Ehrenstorfer (Germany). HMB was the internal standard. The reagents (methanol, dichloromethane, acetone and n-hexane) were of HPLC grade and obtained from Fisher (USA). Uncultivated Soil was collected from the surface horizon $(0-20 \mathrm{~cm}$ ) in the Hunan, Gansu, Zhejiang, Jiangxi, Jilin and Guangdong provinces of China. Th six soil samples were air dried, ground and passed through 2- and $0.25-\mathrm{mm}$ sieves. The $\mathrm{pH}$ of soil samples was measured in a 1:0.5 soil/water suspension, total organic carbon (TOC) was determined by the oxidation method with $\mathrm{K}_{2} \mathrm{Cr}_{2} \mathrm{O}_{7}-\mathrm{H}_{2} \mathrm{SO}_{4}$. Basic properties of the soil samples are described in Table $\mathrm{S} 1$ of Supporting information (SI).

\section{Aggregate size fractionation of soils}

Aggregate size fractionation of the bulk soil was conducted for soils 1-6 based on mechanical dispersion. The detailed fractionation procedures are described in Table S2. After fractionation, 50-200 $\mu \mathrm{m}, 5-50 \mu \mathrm{m}, 1-5 \mu \mathrm{m}$ and $<1 \mu \mathrm{m}$ fractions were freeze-dried and then weighed.

\section{Treatment of soil samples with hydrofluoric acid (HF)}

Hydrofluoric acid can effectively remove paramagnetic species and also concentrate organic matter by removing most soil minerals (Ahmad et al. 2001). Briefly, the HF-treatment consisted of twelve successive treatments with $2 \% \mathrm{HF}$ solution. Each treatment involved shaking $5 \mathrm{~g}$ soils (the bulk soil and their different aggregate fractions respectively) in $50 \mathrm{~mL}$ of $2 \% \mathrm{HF}$ solution and filtered through $0.45 \mu \mathrm{m}$ Teflon filters, end-over-end, for periods of $0.5 \mathrm{~h}$ ( 2 times), $1 \mathrm{~h}$ ( 2 times), $2 \mathrm{~h}$ ( 7 times) and $16 \mathrm{~h}$ (once). After the final extraction, the residue was washed three times with deionized Millipore water for shaking 10 mins and the supernatant solution was discarded and then freeze-dried.

\section{Sorption batch experiments}

Sorption was measured using a batch equilibrium technique. The weighted bulk soil and their different aggregate fractions ( $50 \mathrm{mg}$ ) were accurately and separately weighed into $50 \mathrm{~mL}$ centrifuge glass bottles with screw caps and equilibrated with $50 \mathrm{~mL}$ of $0.005 \mathrm{~mol} \cdot \mathrm{L}^{-1} \mathrm{CaCl}_{2}$ solution (containing $100 \mathrm{mg} \cdot \mathrm{L}^{-1}$ $\mathrm{NaN}_{3}$ to inhibit microbial activity) containing $15 \mathrm{ng} \cdot \mathrm{mL}^{-1}$ of HHCB and AHTN. Then the mixtures were shaken at $25^{\circ} \mathrm{C}$ on an orbital shaker: when all the selected soils had shaken for $0.5 \mathrm{~h}, 1 \mathrm{~h}, 2 \mathrm{~h}, 4 \mathrm{~h}, 8 \mathrm{~h}, 12 \mathrm{~h}$, $18 \mathrm{~h}, 24 \mathrm{~h}$ and $48 \mathrm{~h}$, each soil sample was centrifuged for $5 \mathrm{mins}$ at a speed of $8000 \mathrm{r} \cdot \mathrm{min}^{-1}$. One series of 
vials without soil as control was also monitored. After centrifugation, $10 \mathrm{~mL}$ of supernatant was taken for solid phase extraction (SPE), and the volume was constant to $0.5 \mathrm{~mL}$, the filtrate was analyzed using Gas Chromatography-Mass Spectrometer (GC-MS). All experiments were conducted in two replicates. The adsorbed amount of HHCB and AHTN was calculated from the difference between the initial and final concentration in solution. The sorption partition coefficients $\left(K_{\mathrm{d}}\right)$ and $K_{\mathrm{oc}}$ were also determined. The mathematical manipulation of the sorption data is described in SI. Freundlich sorption isotherm were employed to fitted the sorption process and relative parameters were given in Table S3.

\section{GC-MS analysis}

Sample analysis was performed with an Agilent 6890N-5975B gas chromatography-mass selective detector (GC-MSD, Agilent Technologies, USA), equipped with a UA-5 column (30 m×0.25 mm, $0.25 \mu \mathrm{m}$ film thickness) and using negative chemical ionization ( $\mathrm{NCl}$ ) in the selected ion monitoring (SIM) mode. The initial oven temperature was maintained at $100{ }^{\circ} \mathrm{C}$ for 5 mins, programmed at a rate of $40{ }^{\circ} \mathrm{C} \cdot \mathrm{min}^{-1}$ to $180{ }^{\circ} \mathrm{C}$, then $5^{\circ} \mathrm{C} \cdot \mathrm{min}^{-1}$ to $220^{\circ} \mathrm{C}$, held for another $2 \mathrm{mins}$, then $30^{\circ} \mathrm{C} \cdot \mathrm{min}^{-1}$ to $280{ }^{\circ} \mathrm{C}$. A $2 \mu$ l extract of sample was injected automatically in splitless mode. Helium was used as carrier gas, and using a splitless time of 0.75 mins with constant column flow of $1.0 \mathrm{~mL} \cdot \mathrm{min}^{-1}$. The MSD was operated in Elmode at $70 \mathrm{eV}$, and the temperatures of the ion source and quadrupole were set at $230{ }^{\circ} \mathrm{C}$ and $280{ }^{\circ} \mathrm{C}$, respectively. The internal standard calibration procedure was used for quantification of PCMs.

\section{QA/QC}

Procedure blanks were run with each batch of samples to evaluate possible contamination during analysis and concentrations of PCMs were below the limit of quantification (LOQ) in all cases. The recoveries of indicator in the soil and water samples ranged from $50.1-120 \%$ and from $67.5-83.7 \%$ for solvent PCMs, respectively. The LOQs of PCMs were estimated as the concentration when a signal-tonoise ratio was 10:1 ( $\mathrm{S} / \mathrm{N}=10)$. The LOQs were $0.3 \mathrm{ng} / \mathrm{L}$ and $0.5 \mathrm{ng} / \mathrm{L}$ for HHCB and AHTN respectively.

\section{Results And Discussion}

\section{PCM sorption among bulk soils and different aggregate fractions}

Good correlations have been observed

between the SOM content and the sorption of many pesticides

Good correlations have been observed

between the SOM content and the sorption of many pesticides 
The partition theory assumed that $K_{\mathrm{oc}}$ value was generally constant for a particular chemical sorption on different soils where sorption is related to the 'quantity' of TOC in the soil. While the result shown that the $K_{\mathrm{oc}}$ value varied greatly among all soils. The $K_{\mathrm{oc}}$ value range from $185 \mathrm{~L} \cdot \mathrm{g}^{-1}$ to $815 \mathrm{~L} \cdot \mathrm{g}^{-1}$ for $\mathrm{HHCB}$ and $152 \mathrm{~L} \cdot \mathrm{g}^{-1}$ to $822 \mathrm{~L} \cdot \mathrm{g}^{-1}$ for AHTN among six bulk soils. The bulk soil 5 had the highest $K_{\text {oc }}$ values and the $K_{\mathrm{oc}}$ value were lowest in bulk soil 2 (Fig. 1). Additionally, the $K_{\mathrm{oc}}$ variation was also large in different aggregates fractions of soils for both two PCMs. The obtained $K_{\mathrm{oc}}$ value in $<1 \mu \mathrm{m}$ aggregates fractions spread out in a wide range: $227 \mathrm{~L} \cdot \mathrm{g}^{-1}$ to $895 \mathrm{~L} \cdot \mathrm{g}^{-1}$ for $\mathrm{HHCB}$; and $258 \mathrm{~L} \cdot \mathrm{g}^{-1}$ to $819 \mathrm{~L} \cdot \mathrm{g}^{-1}$ for AHTN. In 1$5 \mu \mathrm{m}$ aggregates fractions, the $K_{\mathrm{oC}}$ value range from $147 \mathrm{~L} \cdot \mathrm{g}^{-1}$ to $450 \mathrm{~L} \cdot \mathrm{g}^{-1}$ for $\mathrm{HHCB}$; and $148 \mathrm{~L} \cdot \mathrm{g}^{-1}$ to $280 \mathrm{~L} \cdot \mathrm{g}^{-1}$ for AHTN. The $K_{\mathrm{oc}}$ value range from $126 \mathrm{~L} \cdot \mathrm{g}^{-1}$ to $291 \mathrm{~L} \cdot \mathrm{g}^{-1}$ for HHCB and $148 \mathrm{~L} \cdot \mathrm{g}^{-1}$ to 311 $\mathrm{L} \cdot \mathrm{g}^{-1}$ for AHTN in 5-50 $\mu \mathrm{m}$ aggregates fractions. In 50-200 $\mu \mathrm{m}$ aggregates fractions, the $K_{\text {oc }}$ value range from $53 \mathrm{~L} \cdot \mathrm{g}^{-1}$ to $343 \mathrm{~L} \cdot \mathrm{g}^{-1}$ for HHCB and $51 \mathrm{~L} \cdot \mathrm{g}^{-1}$ to $236 \mathrm{~L} \cdot \mathrm{g}^{-1}$ for AHTN.

Some studies showed that sorption was highest at the smaller soil fractions $(<2 \mu \mathrm{m})$ due to their higher specific surface area and the presence of more humified organic material (Liu et al. 2010, Wang and Keller 2009, De Jonge et al. 2000). However, in the present study, the greatest $K_{\mathrm{oc}}$ values did not always occur in the smaller soil fractions ( $<1 \mu \mathrm{m}$ aggregates fractions). The bulk soil and the $5-50 \mu \mathrm{m}$ aggregates fractions also yielded the largest $K_{\mathrm{oc}}$ values under specific soil conditions (e.g., with bulk soil in soil 3 , soil 5 and soil 6 , and the $5-50 \mu \mathrm{m}$ aggregates fraction in soil 2 for both HHCB and AHTN). The 50-200 $\mu \mathrm{m}$ aggregates fraction in all soils had the smallest $K_{\text {oc }}$ except soil 5 . There was a significant difference in the $K_{\mathrm{oc}}$ value of the same soil with different aggregates fractions. Some studies explained this phenomenon that different humic fractions from the same soil may resulted in different $K_{\mathrm{oc}}$ values (Kang and Xing 2005, Gunasekara and Xing 2003, Mao et al. 2002).

Based on the distribution of different particle size in soils as shown in Fig.S1, the contributions of different aggregate fractions to HHCB and AHTN sorption by soils were calculated as described in SI. Sorption mass balances revealed that the calculated values, based on the sum of the amount of equilibrium sorption of HHCB and AHTN in each fraction, were unmatched the measured values in bulk soils (Fig. 2). The sum of sorption contribution in each fraction were greater than the measured values in bulk soils 2 and soil 4. Bonin and Simpson (2007) hold that sorption sites may expose after physical fractionation within SOM that are closely associated with minerals and typically not accessible in bulk soils. However, the sum of sorption contribution in each fraction were significantly different with the measured values in other bulk soils. Wang et al. (2018) explained this phenomenon that if the formation of organic-mineral complex came solely from the selective combination of minerals with SOM, with no accompanying changes to the properties of the SOM, then the sorption capacity of organic-mineral complex should be less than or equal to the sum of the capacity of the two components. This suggested that it was likely that the accessible SOM, rather than total SOM, governed the extent of the target sorption (He et al. 2014, Chen et al. 2005). 
The 5-50 $\mu \mathrm{m}$ fractions accounted for the most contribution to total sorption in bulk soils for both HHCB and AHTN, about $7.02-37.1 \%$ in the $50-200 \mu \mathrm{m}$ fractions, $1.20 \%$ to $44.5 \%$ in the $1-5 \mu \mathrm{m}$ fractions and just $0.93-21.6 \%$ of total sorption by the $<1 \mu \mathrm{m}$ fractions. Although the $<1 \mu \mathrm{m}$ fractions in soil 4 had the highest $K_{\mathrm{oc}}$ value (Fig. 1), the sorption contribution is the smallest in all particle aggregate fractions for both HHCB and AHTN. Compared with other aggregate fractions, the $K_{\mathrm{oc}}$ value in 5-50 $\mu \mathrm{m}$ fractions were relatively lower among all soils except soil 2 (Fig. 1). However, the contributions to HHCB and AHTN sorption in 5-50 $\mu \mathrm{m}$ fractions were much higher than others aggregate fraction. It could be the reason that the content of 5-50 $\mu \mathrm{m}$ fractions were relatively higher than the other fraction in bulk soils. This further indicated that the contributions of different aggregate fractions to HHCB and AHTN sorption by soils were not only influenced by $K_{\mathrm{oc}}$ value but also the content.

\section{$\mathrm{K}_{\text {oc }}$ variation before versus after $\mathrm{HF}$ treatment}

Table S4 and Table S5 shown the TOC content of SOM (foc) in different aggregate fractions and bulk soil before and after HF-treatment, respectively. In Table S4, as it ranged from 83.5-101.8\%, the sum percentage of foc in different aggregate fractions were matched with the foc in the most corresponding bulk soils. The systematic and analytical errors during the physical fractionation procedures were negligible. In Table S5, the HF-treatment increased the TOC content of the soils and different aggregate fractions by a factor of 1.13-27.0 (average 4.1). From Fig. S2, it was apparated that corresponding $\Delta K_{\mathrm{oc}}$ values for whole soils and $\triangle T O C$ content was only weakly correlated, a fact confirmed by linear regression $\left(\mathrm{R}^{2}=0.230\right.$ for $\mathrm{HHCB}, \mathrm{R}^{2}=0.224$ for $\left.\mathrm{AHTN}\right)$. It was interesting that the greater $\Delta K_{\text {oc }}$ values were appeared at low $\triangle \mathrm{TOC}$. The removal of minerals with HF treatment from soils changed the extent of HHCB and AHTN sorption. With the depletion of minerals, the $K_{\mathrm{oc}}$ decreased for HHCB and AHTN in all soils respectively (Fig. 3 and Fig S3). This finding was consistent with a previous study (He et al. 2014), which reported a much tighter range of increases in $K_{\mathrm{oc}}$ on $\mathrm{H}_{2} \mathrm{O}_{2}$-treatment. These indicated that the minerals may directly contribute to the sorption or of HHCB and AHTN by soils or organic-mineral interactions can increase $K_{\mathrm{oc}}$ in whole soils. He et al. (2014) hold that the newly formed sorption sites on the soil minerals increased the $K_{\mathrm{oc}}$ in those aggregate fractions after the chemical removal of SOM. While in this study, we can only speculate that some sorption sites may appear on the soil minerals, which lead to the decreased of $K_{\text {oc }}$ in bulk soil.

However, the $K_{\mathrm{oc}}$ values in different aggregate fractions were not always decreased after HF treatment. Instead, the $K_{\text {oc }}$ increased in 50-200 $\mu \mathrm{m}$ fraction or 5-50 $\mu \mathrm{m}$ fraction of all soils except soil 1 . This indicated that, the organic-mineral interaction blocked sorption in these aggregate fractions. An increase

in $K_{\mathrm{oc}}$ value on HF-treatment or a decrease in $K_{\mathrm{oc}}$ of the soils after SOM removal were also previously reported (Bonin and Simpson 2007, Ahangar et al. 2008, Smernik and Kookana 2015). Smernik and Kookana (2015) proposed that it is the liberation of SOM sorption sites blocked by interactions with minerals in the whole soils. Bonin and Simpson (2007) believed that physical fractionation may expose sorption sites within SOM that are closely associated with minerals and typically not accessible in bulk soils. Other investigators explained these results with the hypotheses of chemical alteration of the SOM 
components (Rumpel et al. 2006, Zegouagh et al. 2004) and SOM conformational changes (Salloum, Dudas and McGill 2001). However, the $K_{\mathrm{oc}}$ value in $<1 \mu \mathrm{m}$ fractions were decreased among all soils. This suggested that the organic-mineral interaction promoted sorption in this fraction. Therefore, we proposed that maybe it was not sorption site of SOM but minerals were blocked in $<1 \mu \mathrm{m}$ fractions lead to $K_{\mathrm{oc}}$ decreased. In soil 1 and soil 6 , there was little change on $K_{\text {oc }}$ after the HF treatment for the $50-200 \mu \mathrm{m}$ fraction and the $1-5 \mu \mathrm{m}$ fraction. Even though the $\Delta \mathrm{TOC}$ content increased from 6.12 to 153.1(Table S4, Table S5), but there was little contribution to sorption. This shown that the organic-mineral interaction may also have little effect on sorption, only accessible SOM govern the content of target sorption. Many distinct organo-mineral complexes were distributed in different aggregate fractions and bulk soils due to the SOM bonded to minerals by various forms (Garbarini and Lion 1986), which could be the reason caused the different effects of organic-mineral interaction on both the bulk soil and different aggregate fractions to sorption. The different sized organic-mineral complexes in soils differed significantly in structure and composition due to different strengthen of organic-mineral associations (He et al. 2008). It can thus be inferred that the effect of interactions between soil minerals and SOM were dual for the sorption of HHCB and AHTN.

It should also be noted that HF-treatment reduced the variability in $K_{\mathrm{oc}}$ among the bulk soils. The coefficient of variation (standard deviation divided by the mean) was about $60 \%$ for both two PCMs in bulk soils and reduced to $33 \%$ for HHCB and $47 \%$ for AHTN. This indicated that the nature of soil minerals is an important contributor to $K_{\mathrm{oc}}$ variability. However, another finding reported that the coefficient of variation of $K_{\mathrm{oc}}$ for diuron was almost the same between the before and the after HFtreatment (Smernik and Kookana 2015). While in these four aggregates fractions, HF-treatment increased $K_{\mathrm{oc}}$ variation. The chemical characteristics of organic matter of among six selected soils and their different aggregates fractions might differed. As pointed out by Ahmad et al. (2001), structural differences in the SOM are related to various factors such as degree of decomposition of the organic matter, origin, parent material, and environmental factors. This suggested that maybe the nature of accessible SOM mainly control the sorption process in aggregates fractions of soils. Variations in organic matter chemistry between different aggregates fractions of soils may contribute to $K_{\mathrm{oc}}$ variability (Ahangar et al. 2008). Besides, it was possible that the mechanism of organic-mineral interaction in different aggregate fractions was also different, which in turn affects its sorption contribution in the bulk soil.

In order to explore the effects of the organic-mineral interaction in different aggregate fractions on the bulk soil sorption, we calculated the overlay value of $\Delta K_{\mathrm{oc}}$, the details of calculation were described in SI. If there is no interaction between different sizes particles, the measured $\Delta K_{\mathrm{oc}}$ value should match the overlay $\Delta K_{\mathrm{oc}}$ value. Comparing the overlay $\Delta K_{\mathrm{oc}}$ value with the measured $\Delta K_{\mathrm{oc}}$ value, it was obviously unmatched each other (Fig. 3 and Fig.S3). In soil 1, soil 3 and soil 4 , both the overlay $\Delta K_{\text {oc }}$ value and the measured $\Delta K_{\mathrm{oc}}$ value indicated that the interaction of organic-minerals promoted sorption, but the strengthen of promotion of sorption is different between the two $\Delta K_{\mathrm{oc}}$ values. In soil 2, soil 5 and soil 6 , 
the measured $\Delta K_{\mathrm{oc}}$ value suggested organic-mineral interaction was positive to sorption but the calculated $\Delta K_{\mathrm{oc}}$ value shown that organic-mineral interaction blocked the sorption. Due to the components in different aggregate sizes were not dispersed and independent, but interacted with each other, such as wrapping, covering and so on. As a result, there was a significant difference between the overlay $\Delta K_{\mathrm{oc}}$ value and the measured $\Delta K_{\mathrm{oc}}$ value, which was manifested in the effect and strengthen of organic-mineral interaction on the sorption. Due to the chemical characteristics or nature of SOM varied with different aggregate size, the effect of organic-mineral interaction to bulk soil sorption was also different. The interaction in the $<1 \mu \mathrm{m}$ fractions promoted sorption while in the $50-200 \mu \mathrm{m}$ fractions organic-mineral interaction blocked the sorption in the same soils. However, even for components with the same aggregate size, the effect and strengthen of interaction to sorption were different in soils. The organic-mineral interaction in 5-50 $\mu \mathrm{m}$ fractions promoted sorption in soil 1 , soil 3 , soil 4 and soil 5 but blocked sorption in soil 2 and soil 6 . The organic-mineral interaction in 1-5 $\mu \mathrm{m}$ fractions blocked sorption in all selected soils except soil 5. Accordingly, the effect of organic-mineral interactions to bulk soil sorption in different aggregate fractions were different, which could explain the $K_{\mathrm{oc}}$ variation in bulk soil to some extent.

\section{Conclusions}

The sorption batch experiment carried out as well as the $K_{\text {oc }}$ values determined about the two PCM indicated that they were adsorbed to soils very strongly. The effects of organic-mineral interactions on PCMs sorption across a diverse range of soils and their different aggregate fractions were also investigated. The result showed that organic-mineral interactions is an important reason of $K_{\text {oc }}$ variety in all soils with different physical and chemical properties. The organic-mineral interaction promoted sorption with different strength in the bulk soil and $<1 \mu \mathrm{m}$ fractions, hindered the PCMs sorption in the $50-200 \mu \mathrm{m}$ fractions of all soils. The effects of organic matter-mineral interactions in 5-50 $\mu \mathrm{m}$ and 1-5 $\mu \mathrm{m}$ fractions were different among selected soils. The dual impact of organic-mineral interactions during HHCB and AHTN sorption in contrasting nature soils. Furthermore, the sorption contribution of different aggregate fractions was influenced by both $K_{\mathrm{oc}}$ and the content. The effect of organic-mineral interaction in different particle size to sorption was different, which result in the $K_{\mathrm{oc}}$ variation in bulk soils to some extent.

\section{Declarations}

Acknowledgment We acknowledge the support provided by China Scholarship Council during a visit of Qingwei Bu to the University of Georgia.

Authors' contributions Qingwei Bu designed, planned, conceptualized, performed the analysis, drafted the original manuscript, funding acquisition, and project administered, Hongmei Cao was involved in performing the analysis, and drafting the original manuscript; Dongkui Wu and Zhou Ming were involved in statistical analysis, and proofreading. All authors have approved the final version of the manuscript. 
Funding This work was co-supported by the National Natural Science Foundation of China (grant no. 21777188) and the Fundamental Research Funds for the Central Universities in China (grant no. 2020YJSHH20). Qingwei Bu was also funded by Yue Qi Young Scholar Project, China University of Mining \& Technology, Beijing (grant no. 2017QN15).

Data availability The datasets used and/or analyzed during the current study are available from the corresponding author on reasonable request.

Conflicts of interest The authors declare that they have no competing interests.

\section{References}

1. Ahangar, A. G., R. J. Smernik, R. S. Kookana \& D. J. Chittleborough (2008) Separating the effects of organic matter-mineral interactions and organic matter chemistry on the sorption of diuron and phenanthrene. Chemosphere 74, 1062-1068.

2. Ahmad, R., R. S. Kookana, A. Alston \& J. O. Skjemstad (2001) The nature of soil organic matter affects sorption of pesticides. 1. Relationships with carbon chemistry as determined by 13C CPMAS NMR spectroscopy. Environ. Sci. Technol, 35, 878-884.

3. Ahmad, R., P. N. Nelson \& R. S. Kookana (2006) The molecular composition of soil organic matter as determined by $13 \mathrm{C}$ NMR and elemental analyses and correlation with pesticide sorption. European Journal of Soil Science, 57, 883-893.

4. Amelung, W., W. Zech, X. Zhang, R.F. Follett, H. Tiessen, E. Knox \& K. W. Flach (1998) Carbon, nitrogen, and sulfur pools in particle-size fractions as influenced by climate. Soil Sci. Soc. Am. J, 62, 172-181.

5. Azaroff, A., C. Miossec, L. Lanceleur, R. Guyoneaud \& M. Monperrus (2020) Priority and emerging micropollutants distribution from coastal to continental slope sediments: A case study of Capbreton Submarine Canyon (North Atlantic Ocean). Sci Total Environ, 703, 135057.

6. Balk, F. \& R. A. Ford (1999) Environmental risk assessment for the polycyclic musks AHTN and HHCB in the EU. I. Fate and exposure assessment. Toxicol Lett, 111, 57-79.

7. Bonfleur, E. J., R. S. Kookana, V. L. Tornisielo \& J. B. Regitano (2016) Organomineral interactions and herbicide sorption in brazilian tropical and subtropical oxisols under No-Tillage. J Agric Food Chem, 64, 3925-34.

8. Bonin, J. L. \& M. J. Simpson (2007) Variation in phenanthrene sorption coefficients with soil organic matter fractionation: The result of structure or conformation? Environ. Sci. Technol, 41, 153-159.

9. Chen, B., E. J. Johnson, B. Chefetz, L. Zhu \& B. Xing (2005) Sorption of polar and nonpolar aromatic organic contaminants by plant cuticular materials: role of polarity and accessibility. Environ. Sci. Technol., 39, 6138-6146.

10. De Jonge, L. W., H. de Jonge, P. Moldrup, O. H. Jacobsen \& B. T. Christensen (2000) Sorption of prochloraz on primary soil organo-mineral size separates. J. Environ. Qual., 29, 206-213. 
11. Farenhorst, A., I. M. Saiyed, T. B. Goh \& P. McQueen (2010) The important characteristics of soil organic matter affecting 2,4-dichlorophenoxyacetic acid sorption along a catenary sequence. $J$ Environ Sci Health B, 45, 204-13.

12. Garbarini, D. R. \& L. W. Lion (1986) Influence of the nature of soil organics on the sorption of toluene and trichloroethylene. Environ. Sci. Technol, 20, 1263-1269.

13. Gooding, M. P., T. J. Newton, M. R. Bartsch \& K. C. Hornbuckle (2006) Toxicity of synthetic musks to early life stages of the freshwater mussel Lampsilis cardium. Arch Environ Contam Toxicol, 51, 54958.

14. Gunasekara, A. S. \& B. Xing (2003) Sorption and desorption of naphthalene by soil organic matter: importance of aromatic and aliphatic components. J Environ Qual, 32, 240-6.

15. He, Y., Z. Liu, P. Su, X. Shen, P. C. Brookes \& J. Xu (2014) A new adsorption model to quantify the net contribution of minerals to butachlor sorption in natural soils with various degrees of organo-mineral aggregation. Geoderma, 232-234, 309-316.

16. He, Y., Z. Liu, J. Zhang, H. Wang, J. Shi \& J. Xu (2011) Can assessing for potential contribution of soil organic and inorganic components for butachlor sorption be improved? J Environ Qual, 40, 1705-13.

17. He, Y., Z. H. Xu, C. R. Chen, J. Burton, Q. Ma, Y. Ge \& J. M. Xu (2008) Using light fraction and macroaggregate associated organic matters as early indicators for management-induced changes in soil chemical and biological properties in adjacent native and plantation forests of subtropical Australia. Geoderma, 147, 116-125.

18. Kang, S. \& B. Xing (2005) Phenanthrene sorption to sequentially extracted soil humic acids and humins. Environ Sci Technol, 39, 134-40.

19. Kannan, K., J. L. Reiner, S. H. Yun, E. E. Perrotta, L. Tao, B. Johnson-Restrepo \& B. D. Rodan (2005) Polycyclic musk compounds in higher trophic level aquatic organisms and humans from the United States. Chemosphere, 61, 693-700.

20. Lange, C., B. Kuch \& J. W. Metzger (2015) Occurrence and fate of synthetic musk fragrances in a small German river. $J$ Hazard Mater, 282, 34-40.

21. Liu, Z., Y. He, J. Xu, P. Huang \& G. Jilani (2008) The ratio of clay content to total organic carbon content is a useful parameter to predict adsorption of the herbicide butachlor in soils. Environ Pollut, $152,163-71$.

22. Liu, Z. Z., N. Ding, T. Hayat, Y. He, J. M. Xu \& H. Z. Wang (2010) Butachlor sorption in organically rich soil particles. Soil Sci. Soc. Am. J, 74, 2032-2038.

23. Luckenbach, T. \& D. Epel (2005) Nitromusk and polycyclic musk compounds as long-term inhibitors of cellular xenobiotic defense systems mediated by multidrug transporters. Environmental Health Perspectives, 113, 17-24.

24. Lyu, Y., S. Ren, F. Zhong, X. Han, Y. He \& Z. Tang (2021) Synthetic musk fragrances in sediments from a subtropical river-lake system in eastern China: occurrences, profiles, and ecological risks. Environ Sci Pollut Res Int, 28, 14597-14606. 
25. Mao, J. D., L. S. Hundal, M. L. Thompson \& K. Schmidt-Rohr (2002) Correlation of poly(methylene)rich amorphous aliphatic domains in humic substances with sorption of a nonpolar organic contaminant phenanthrene. Environ Sci Technol, 36, 929-36.

26. Pedersen, S., H. Selck, D. Salvito \& V. Forbes (2009) Effects of the polycyclic musk HHCB on individual- and population-level endpoints in Potamopyrgus antipodarum. Ecotoxicol Environ Saf, 72, 1190-9.

27. Reiner, J. L., C. M. Wong, K. F. Arcaro \& K. Kannan (2007) Synthetic musk fragrances in human milk from the United States. Environ Sci Technol, 41, 3815-20.

28. Rimkus, G. G. (1999) Polycyclic musk fragrances in the aquatic environment. Toxicol Lett, 111, 37-56.

29. Rumpel, C., N. Rabia, S. Derenne, K. Quenea, K. Eusterhues, I. Kogel-Knabner \& A. Mariotti (2006) Alteration of soil organic matter following treatment with hydrofluoric acid (HF). Org. Geochem, 37, 1437-1451.

30. Salloum, M. J., M. J. Dudas \& W. B. McGill (2001) Variation of 1-naphthol sorption with organic matter fractionation: the role of physical conformation. Organic Geochemistry, 32, 709-719.

31. Savini, M. C., R. M. Loewy, V. E. Nicotra \& M. E. Parolo (2016) Contribution of soil components on the sorption of chlorpyrifos. Water, Air, \& Soil Pollution, 228.

32. Schnell, S., R. Martin-Skilton, D. Fernandes \& C. Porte (2009) The interference of nitro- and polycyclic musks with endogenous and xenobiotic metabolizing enzymes in carp: an in vitro study. Environ Sci Technol, 43, 9458-64.

33. Smernik, R. J. \& R. S. Kookana (2015) The effects of organic matter-mineral interactions and organic matter chemistry on diuron sorption across a diverse range of soils. Chemosphere, 119, 99-104.

34. Sumner, N. R., C. Guitart, G. Fuentes \& J. W. Readman (2010) Inputs and distributions of synthetic musk fragrances in an estuarine and coastal environment; a case study. Environ Pollut, 158, 215-22.

35. Wang, F., J. He, B. He, X. Zhu, X. Qiao \& L. Peng (2018) Formation process and mechanism of humic acid-kaolin complex determined by carbamazepine sorption experiments and various characterization methods. J Environ Sci (China), 69, 251-260.

36. Wang, K. \& B. Xing (2005a) Chemical extractions affect the structure and phenanthrene sorption of soil humin. Environ Sci Technol, 39, 8333-40.

37. - (2005b) Structural and sorption characteristics of adsorbed humic acid on clay minerals. J Environ Qual, 34, 342-9.

38. Wang, P. \& A. A. Keller (2009) Sorption and desorption of atrazine and diuron onto water dispersible soil primary size fractions. Water Res, 43, 1448-56.

39. Wang, Q. \& B. C. Kelly (2017) Occurrence and distribution of synthetic musks, triclosan and methyl triclosan in a tropical urban catchment: Influence of land-use proximity, rainfall and physicochemical properties. Sci Total Environ, 574, 1439-1447.

40. Yamauchi, R., H. Ishibashi, M. Hirano, T. Mori, J. W. Kim \& K. Arizono (2008) Effects of synthetic polycyclic musks on estrogen receptor, vitellogenin, pregnane $X$ receptor, and cytochrome P450 3A 
gene expression in the livers of male medaka (Oryzias latipes). Aquat Toxicol, 90, 261-8.

41. Yang, J. J. \& C. D. Metcalfe (2006) Fate of synthetic musks in a domestic wastewater treatment plant and in an agricultural field amended with biosolids. Sci Total Environ, 363, 149-65.

42. Zegouagh, Y., S. Derenne, M. Dignac, E. Baruiso, A. Mariotti \& C. Largeau (2004) Demineralisation of a crop soil by mild hydrofluoric acid treatment: influence on organic matter composition and pyrolysis. J. Anal. Appl. Pyrolysis, 71, 119-135.

43. Zhang, H., Q. Bu, D. Wu \& G. Yu (2020) Polycyclic musks in surface water and sediments from an urban catchment in the megacity Beijing, China. Environ Pollut, 263, 114548.

44. Zhang, X., Y. Yao, X. Zeng, G. Qian, Y. Guo, M. Wu, G. Sheng \& J. Fu (2008) Synthetic musks in the aquatic environment and personal care products in Shanghai, China. Chemosphere, 72, 1553-1558.

45. Zhou, Y. M., R. X. Liu \& H. X. Tang (2004) Sorption interaction of phenanthrene with soil and sediment of different particle sizes and in various $\mathrm{CaCl} 2$ solutions. Journal of Colloid and Interface Science, 270, 37-46.

\section{Figures}
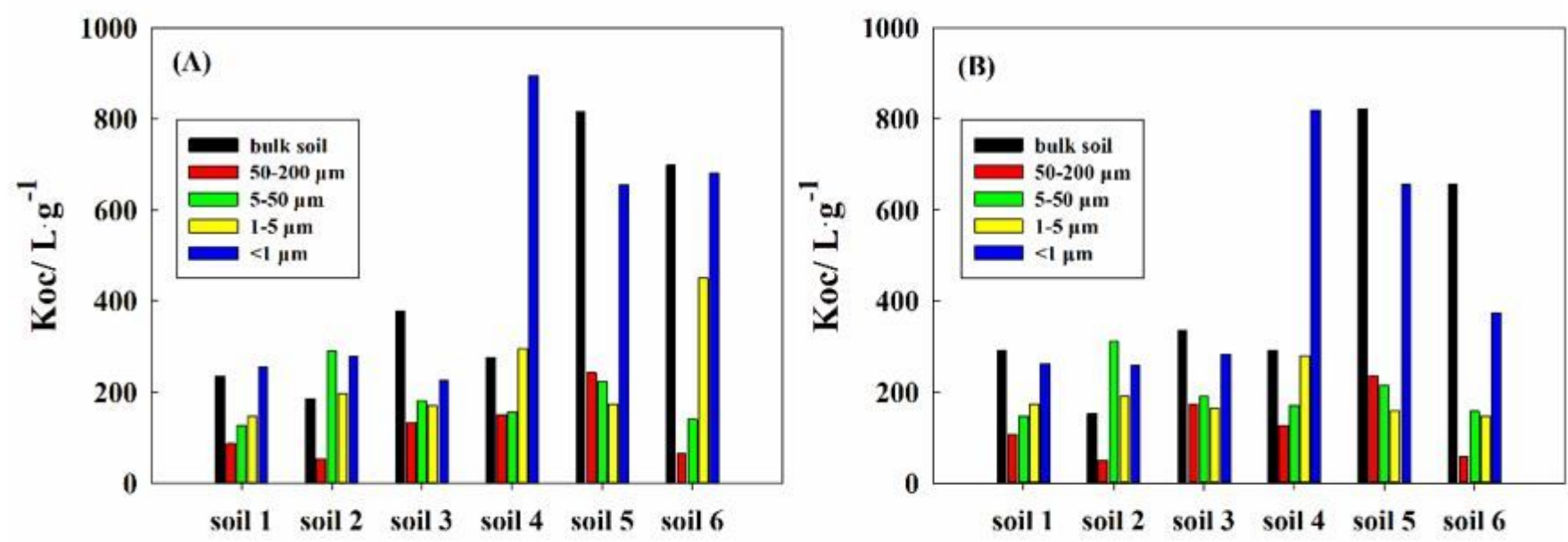

Figure 1

The organic carbon content normalized partition coefficient for HHCB (A) and AHTN (B) in bulk soil and different sized soil aggregate fractions 

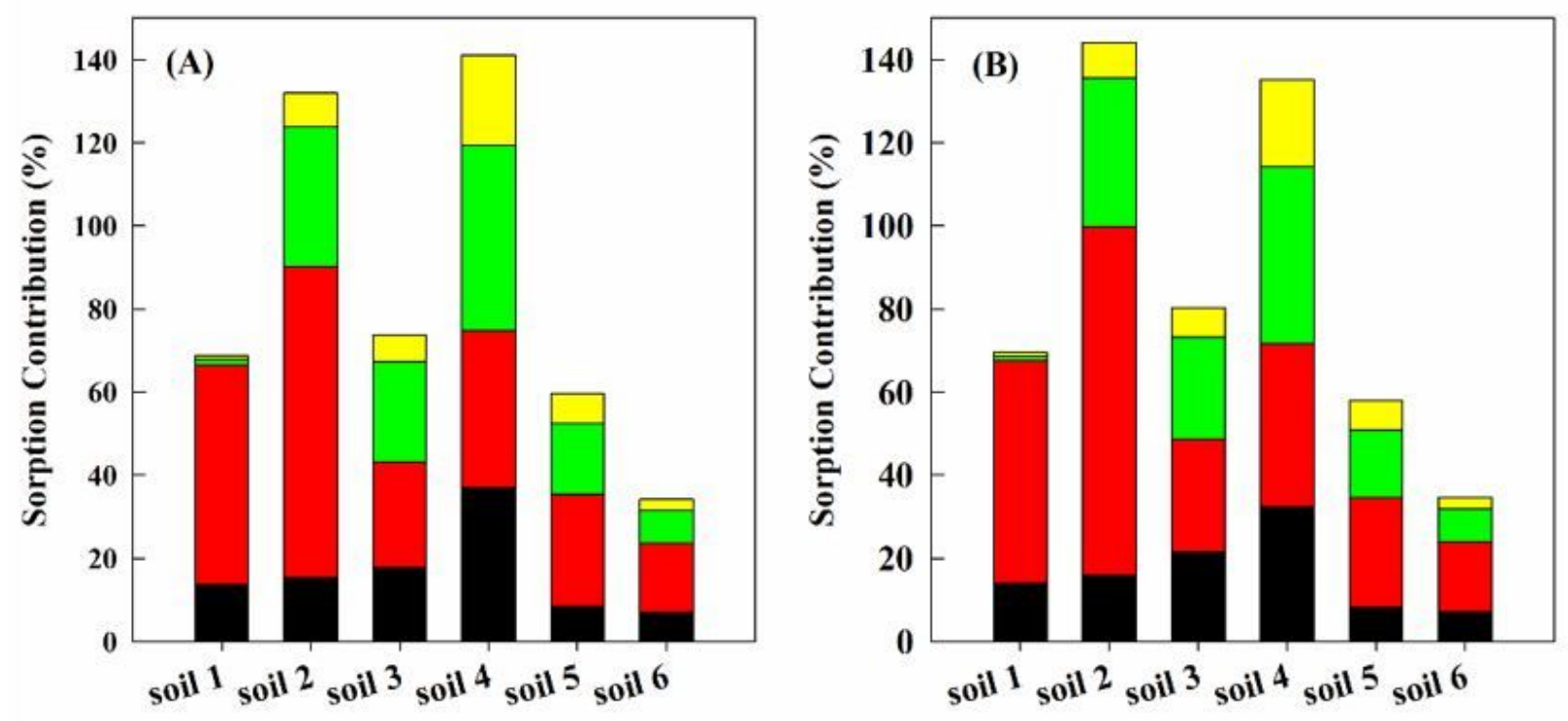

Figure 2

Contribution of different aggregate fractions to the sorption of HHCB (A) and AHTN (B) in soils 

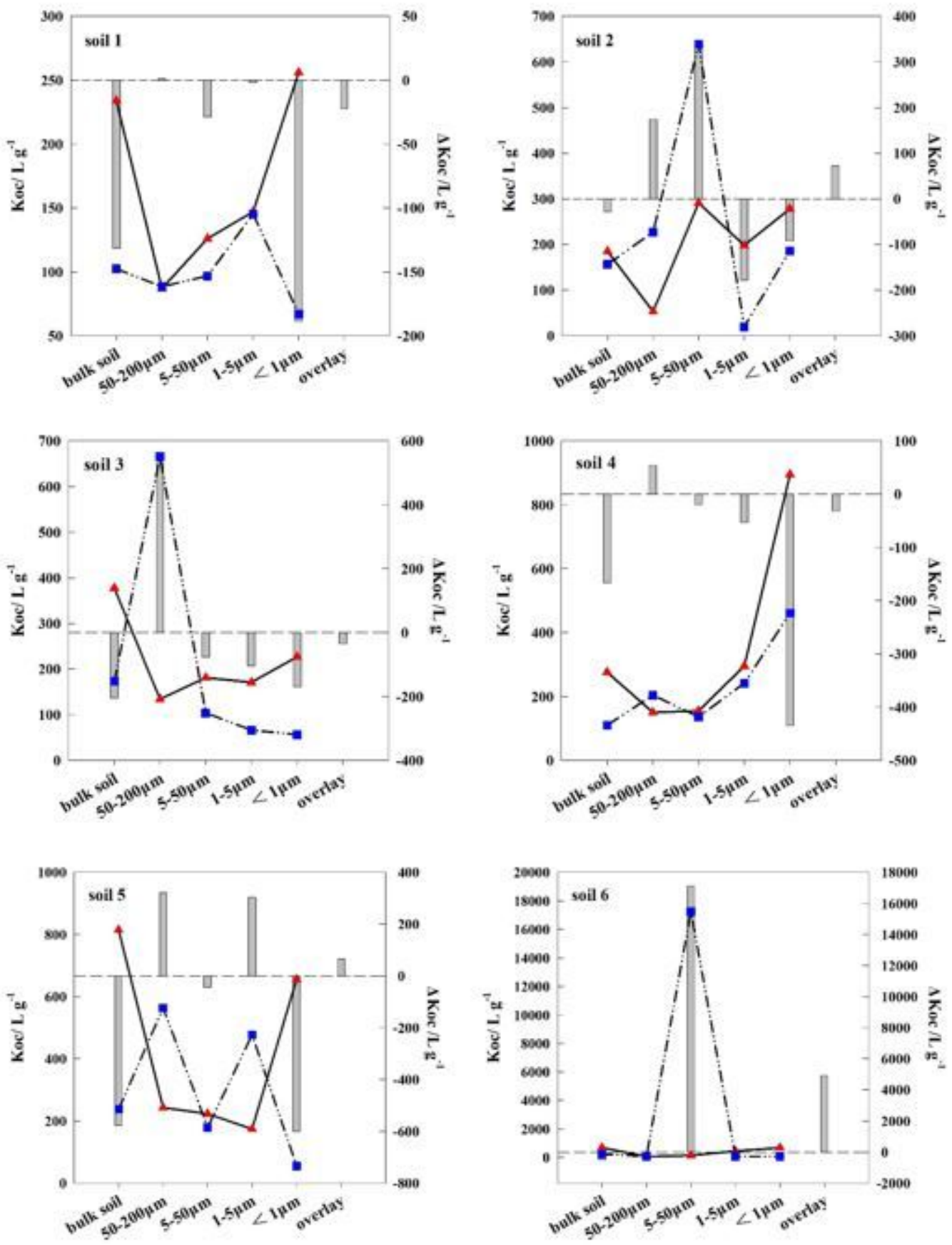

Figure 3

Koc variation of HHCB before and after HF treatment among selected bulk soils and their different aggregate fractions $\Delta \mathrm{Koc}=\mathrm{Koc}$ (after the HF treatment) - Koc (before the HF treatment)

\section{Supplementary Files}

This is a list of supplementary files associated with this preprint. Click to download. 
- supportinginformation.docx

Page 16/16 